\title{
TOPSIS AND MULTI-CHOICE GOAL PROGRAMMING APPROACH TO SUPPLIER SELECTION IN SUPPLY CHAIN MANAGEMENT*
}

\author{
Mohamed A. El-baz and Yehya I. Mesalam** \\ Industrial Eng. Dept., Zagazig University, Egypt
}

\begin{abstract}
Supplier selection decision is vital problem in supply chain management, which involving multiple objectives. In this paper, a formulation of fuzzy multi-choice goal programming (FMCGP) is presented after calculate the closeness confections of each supplier using fuzzy TOPSIS (Techniques for Order Preference by Similarity to Ideal Solution). The proposed approach improves the applicability of goal programming in real world situations and provides useful insight about the solution of a new class of problems. To demonstrate the usefulness of the proposed method, a case study is presented and the proposed approach obtains a better solution than Fuzzy Goal Programming (FGP).
\end{abstract}

KEY WORDS: supplier selection, goal programming, multi choice goal programming. Fuzzy goal programming.

\section{TOPSIS ET MULTI-CHOIX APPROCHE DE PROGRAMMATION POUR BUT DE SÉLECTION DES FOURNISSEURS EN SUPPLY CHAIN MANAGEMENT}

\section{RÉSUMÉ}

Décision de sélection des fournisseurs est un problème vital dans la gestion de la chaîne d'approvisionnement, ce qui en termes d'objectifs multiples. Dans ce papier, une formulation de programmation objectif floue à choix multiples (FMCGP) est présentée après le calcul des confiseries proximité de chaque fournisseur, en utilisant TOPSIS floues (Techniques de préférence Trier par similarité à la solution idéale). L'approche proposée améliore l'applicabilité de la programmation objectif dans des situations du monde réel et fournit un aperçu utile sur la solution d'une nouvelle classe de problèmes. Pour démontrer l'utilité de la méthode proposée, une étude de cas est présentée et l'approche proposée obtient une meilleure solution que de programmation Objectif floue (FGP).

MOTS CLÉS: le choix du fournisseur, de programmation objectif, programmation multi objectif choix. Programmation objectif floue.

\footnotetext{
* Received: 15/1/2011, accepted: 6/2/2012 (Original Paper)

** Contact author (ymesalam@yahoo.com, +2 01015904433)
} 


\section{INTRODUCTION}

Supplier selection decision is an important component of purchasing management companies (Dobler et al., 1990; Willis et al., 1993). Selecting the right suppliers and determining the appropriate orders from them can bring significant benefit in the reduction in purchasing cost, decrease in supplying risk and improved product quality. Accordingly, international organizations usually build long term contracts with main global suppliers and determine the appropriate orders from them based on their characteristics (cost capability, product quality, ontime delivery and service) (Min, 1994; Ghodsypour \& O’Brien, 1998; Chan \& Kumar, 2007). According to suppliers' different characteristics, organizations adopt different strategies such as cost leadership strategy (Porter, 1980), differentiation strategy (Porter, 1980), quick response (Iyer \& Bergen, 1997) and Just-in-time strategy (Schonberger, 1982) to cope with different issues.

It is not easy to utilize published supplier selection models because all coefficients of supplier selection models should be recomputed when an organization changes their supply chain strategy according to marketing needs. In order to express decision makers' (DMs) preference for different supply chain strategies, DMs need the flexibility to determine not only the imprecise target of each goal but also fuzzy relations among goals. When considering the setting of the priority of goals, a decision maker (DM) usually assigns different weights to each goal that they are concerned with. Traditionally, a DM can use analytic hierarchy process (AHP) to structure the problem and determine the weights of each attribute (Liou \& Chuang, 2008; Fazlollahtabar, 2008). However, a DM will suffer from the complicated pair comparison process between the criteria in AHP hierarchy. With AHP, a DM is asked to estimate pair wise comparison ratios with respect to strength of preference between suppliers by using a long questionnaire. It is too complicated for DMs to conduct pair wise comparison because many supplier selection criteria and potential suppliers should be considered simultaneously. Moreover, if the housing criteria hierarchy is not carefully designed, the result of the problem will be invalid and biased. Compared with AHP FGP is much more suitable for DMs to make decisions because it only requires DMs to set their housing goals and constraints. This can help to reduce a DM's evaluation time, and it can be easily implemented with a computer program.

Recently, the supplier selection process has received considerable attention in the marketing management literature. Chen et al. (2006) adopted a fuzzy decision making approach to address the supplier selection problem in the supply chain system. Five benefit criteria were considered, including the profitability of supplier, relationship closeness, technological capability, conformance quality, and conflict resolution. Lin and Chang (2008) claimed that communication, reputation, industry position, relationship closeness, customer responsiveness, and conflict-solving capabilities are important criteria in vendor selection. In addition, the role of organizational size in the supplier selection process has been addressed by Wang et al. (2009).

Over the years, a number of techniques have been proposed to solve the supplier selection problem. The long list of approaches includes linear programming (LP), mathematical programming models, multipleobjective programming, statistical and probabilistic methods, data envelopment analysis (DEA), costbased methods (CBM), case-based reasoning (CBR), neural networks (NN), AHP, analytic network process (ANP), fuzzy set theory, and techniques for order preference by similarity to ideal solution (TOPSIS).

Recently, the integration of different methodologies to supplier selection process has received considerable attention in the supply chain management literature. Faez, Ghodsypour, and O'brien (2009) presented an integrated fuzzy casebased reasoning and mathematical programming method. Ö nüt, Kara, and Isik (2009) developed a supplier evaluation approach based on the ANP and TOPSIS methods to help a telecommunication company in vendor selection. Ha and Krishnan (2008) developed a hybrid model that including AHP, DEA and NN approaches to the supplier selection problem. Kokangul and Susuz (2009) integrated AHP and mathematical programming to consider both non-linear integer and multipleobjective programming under certain constraints to determine the best suppliers. The integrated model uses source data provided by a manufacturing firm to address a real world supplier selection problem. Demirtas and Üstün(2008) introduce an integrated approach of analytic network process (ANP) and 
multi-objective mixed integer linear programming (MOMILP) is proposed to consider both tangible and intangible factors in choosing the best suppliers and define the optimum quantities among selected suppliers to maximize the total value of purchasing and minimize the budget and defect rate. Most recently, Liao and Kao (2011) integrated fuzzy Techniques for Order Preference by Similarity to Ideal Solution (TOPSIS) and multi-choice goal programming (MCGP) approach to solve the supplier selection problem.

In real life, the modeling of many situations may not be sufficient or exact, as the available data are inexact, vague, imprecise and uncertain by nature (Sarami, Mousavi, \& Sanayei, 2009). Moreover, the decision making processes that take place in such situations are also based on uncertain and ill-defined information. In the real practice of supplier selection, firms usually confronts with a high degree of uncertainties and fuzziness. Fuzzy set theory is considered the most effective methods in managing vagueness and uncertainty problems. The concept of fuzzy sets was introduced by Zadeh (1965) to mathematically represent data and information possessing non-statistical uncertainties and to provide formalized tools for dealing with imprecision intrinsic to many problems (Kahraman, Cevik, Ates, \& Güfer, 2007). In order to model such situations, fuzzy set theory was introduced to express the linguistic terms of decision marking processes.

In this study, an integrated fuzzy TOPSIS and FMCGP model is developed to solve multi-sourcing supplier selection problems. First, linguistic values expressed in trapezoidal fuzzy numbers are applied to assess weights and ratings of supplier selection criteria. Second, a hierarchy multi-model based on fuzzy set theory is expressed and fuzzy positive and negative-ideal solutions are used to find each supplier's closeness coefficient. Finally, a FMCGP model based on the tangible constrains regarding the buyer and its suppliers is constructed and solved to assign order qualities to each supplier

Curry and Lazzari (2009) adopted fuzzy concept as linguistic variables to deal consumer preferences. For this, several previous studies have discussed how to approach the different importance of goals in fuzzy goal programming (FGP). Chen and Tsai (2001) formulated FGP incorporating different importance by using an additive model to maximize the sum of achievement degrees from all fuzzy goals. Aköz and Petrovic (2007) proposed a modified FGP method to handle imprecision of the relative importance relations among goals. However, it is difficult to implement a situation when the multiple aspiration levels appear in a goal by using neither the proposed methods from Chen and Tsai (2001) nor the work of Aköz and Petrovic (2007).

The paper is organized as follows. The next section introduces the basic definitions and notations of fuzzy numbers and linguistic variables. Section 3 presents both the GP and FGP approaches. Section 4 presents the fuzzy TOPSIS. Section 5 presents the Fuzzy multi choice goal programming FMCGP. Section 6 presents the proposed integrated Fuzzy TOPSIS and FMCGP approach. Section 7 presents the case study. The finally section presents conclusions and suggestions for future research

\section{BASIC DEFINITIONS AND NOTATION}

Some basic concepts of fuzzy numbers and linguistic variables are now defined

Definition 2.1. A positive trapezoidal fuzzy number $\tilde{\mathrm{n}}$ can be defined as $\left(\mathrm{n}_{1}, \mathrm{n}_{2}, \mathrm{n}_{3}, \mathrm{n}_{4}\right)$ as shown in Fig. 1 . The membership function $\mu_{\tilde{n}}(x)$ is defined as follows:

$$
\mu_{n}(x)=\left\{\begin{array}{cc}
0 & x<n_{1} \\
\frac{z-n_{1}}{n_{2}-n_{1}} & n_{1} \leq x \leq n_{2} \\
1 & n_{2} \leq x \leq n_{3} \\
\frac{x-n_{4}}{n_{12}-n_{4}} & n_{3} \leq x \leq n_{4} \\
0 & x>n_{4}
\end{array}\right.
$$

For a trapezoidal fuzzy number $\tilde{\mathrm{n}}=\left(\mathrm{n}_{1}, \mathrm{n}_{2}, \mathrm{n}_{3}, \mathrm{n}_{4}\right)$, when $\mathrm{n}_{2}=\mathrm{n}_{3}$, the number is called a triangular fuzzy number. A crisp number $\mathrm{k}$ can be expressed as $(\mathrm{k}, \mathrm{k}$, $k, k)$.

Definition 2.2. A matrix $\tilde{A}$ is called a fuzzy matrix, if it contains at least an entry in $\tilde{\mathrm{A}}$ is a fuzzy number (Buckley, 1985).

Definition 2.3. Let $\dddot{m}=\left(\mathrm{m}_{1}, \mathrm{~m}_{2}, \mathrm{~m}_{3}, \mathrm{~m}_{4}\right)$, and $\tilde{\mathrm{n}}=$ $\left(\mathrm{n}_{1}, \mathrm{n}_{2}, \mathrm{n}_{3}, \mathrm{n}_{4}\right)$, be two trapezoidal fuzzy numbers. Then the distance between them can be calculated using the vertex method (see Chen, 2000; Chen et al., 2006): 


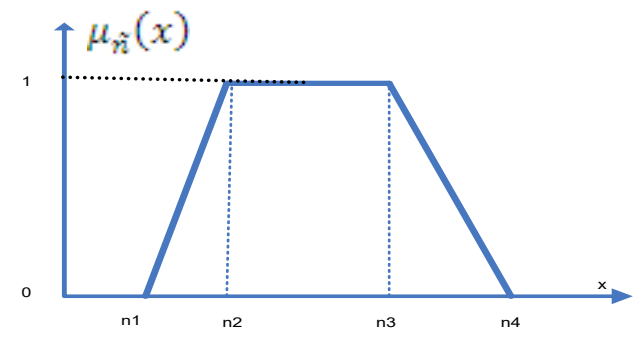

Fig. 1Trapezoidal fuzzy number $\tilde{\mathbf{n}}$

$d(\tilde{m}, \tilde{n})=\left[(1 / 4)\left[\left(m_{1}-n_{1}\right)^{2}+\left(m_{2}-n_{2}\right)^{2}+\right.\right.$

$\left.\left.\left(m_{3}-n_{3}\right)^{2}+\left(m_{4}-n_{41}\right)^{2}\right]\right]^{0.5}$

In this study, the importance weights of various criteria and the ratings of qualitative criteria are considered linguistic variables. Because linguistic assessments approximate the subjective judgment of DMs, we consider linear trapezoidal membership functions adequate for capturing the vagueness of these linguistic assessments. These linguistic variables can be expressed in positive trapezoidal fuzzy numbers, as shown in Figs. 2 and 3. In the proposed integrated model, the DMs use the linguistic variables to evaluate the importance of criteria and the ratings of alternative suppliers with respect to each selection criterion.

\section{FUZZY GOAL PROGRAMMING}

Goal programming (GP) is an analytical multiple objectives decision making approach designed to address decision-marking problems in which targets have been assigned to all attributes and where the decision makers are interested in minimizing the non-achievement of a particular goal (Liao, 2009). The model can take into account many simultaneous objectives as a decision maker seeks the best solution from among a set of feasible solutions. Application of GP to the real life problems may be faced with two important difficulties; expressing the decision maker's vague goals and/or constraints mathematically and optimizing all goals simultaneously.

The original goal programming (GP) technique was first introduced by Charnes and Cooper (1961) and further developed by Lee (1972), Ignizio (1985), Tamiz et al. (1998), and Romero (2001), among others. GP has been applied to many fields such as portfolio selection (Parra, M.A. et al. 2001), acquisitions allocation (Wise and Perushed, 2000), forest planning (Viveira, F.D. et al. 2003), and Chang (2007a, 2008, 2009), among others. So, Goal programming has been, and still is, the most widely used technique for solving multiple criteria decision problems and multiple objective decision problems in finding a set of satisfying solutions. However, the major limitation of goal programming is the aspiration level with scalar value for some multiple objective problems.

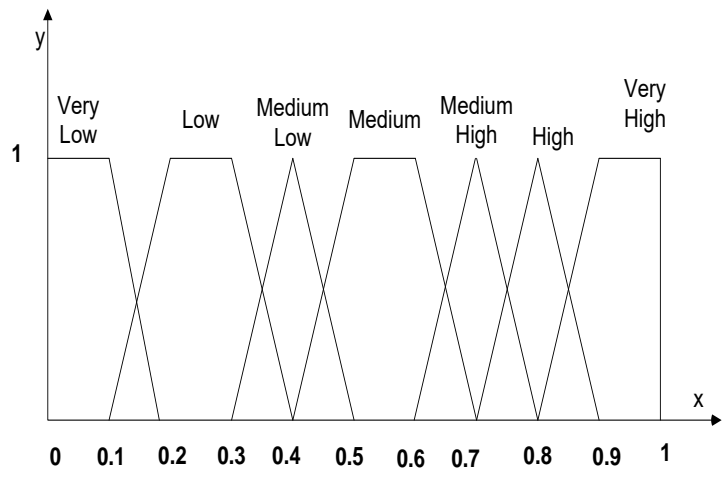

Fig. 2. Linguistic variables for importance weight of each criterion.

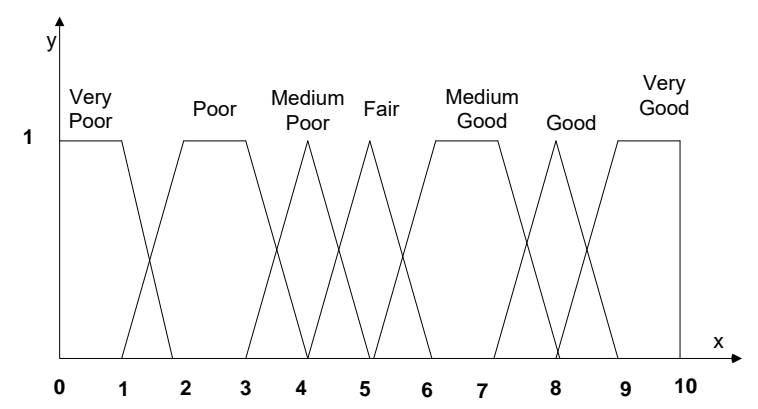

Fig.3. Linguistic variables for ratings.

Since the 1970s, a great deal of work has been done on multiple objective linear programming (MOLP). To date, research on how to solve MOLP problems has been enormous (Ignizio 1985, Lai and Hwang 1994). The methods of MOLP can be classified into three categories: (1) a vector maximization approach, (2) a utility maximization approach, and (3) an aspiration level approach (Lotfi et al. 1997). Aspiration level approach requires DMs to specify the aspiration levels for problem objectives. Many approaches in this category utilize the forms of Goal Programming (GP). In addition, GP is the most widely used technique for solving multi criteria decision problems as well as multi objective decision problems in finding a set of satisfying solutions. The main reason for its popularity lies in its inherent 
flexibility that allows DMs to formulate multiobjective decision problems involving several criteria, incomplete information, many decision variables and resources constraints (Uría et al., 2002).

Fuzzy Set Theory in GP was first considered by Narasimhan (1980). Hannan (1981), Narasimhan (1984), and Tiwari et al (1986) extended the fuzzy theory to the field of GP. Ohta and Yamaguchi (1996), Wang and Fu (1997), Mohammed (2000), ElWahed and Abo-sinna (2001), and Anion and Güngr (2001) have investigated various aspects of decision problems using FGP theoretically. If there are no priorities and also no relative importance assigned to objectives, formulation of the FGP model is same as in general Fuzzy Linear Programming (FLP) model. The main difference between FGP and FLP is that FLP uses the definite intervals determined from solutions of the LP models and so the solution does not change from decision maker to decision maker, whereas in FGP, aspiration levels are specified by decision maker and reflect relative flexibility.

The FGP has the advantage of allowing for the vague aspirations of DMs, which can be qualified using some natural language or vague phenomena. To represent the preference concept of DMs, the preference-based membership functions are introduced below.

for $f_{i}(X) \geq g_{i}$

$\mu_{i}(X)= \begin{cases}1, & \text { if } f_{i}(X) \geq g_{i} \\ \frac{\left(f_{i}(X)-l_{i}\right)}{g_{i}-l_{i}}, & \text { if } l_{i} \leq f_{i}(X) \leq g_{i} \\ 0, & \text { if } f_{i}(X) \leq l_{i}\end{cases}$

for $f_{i}(X) \leq g_{i}$

$\mu_{i}(X)= \begin{cases}1, & \text { if } f_{i}(X) \leq g_{i} \\ \frac{\left(u_{i}-f_{i}(X)\right)}{u_{i}-g_{i}}, & \text { if } g_{i} \leq f_{i}(X) \leq u_{i i} \\ 0, & \text { if } f_{i}(X) \geq u_{i}\end{cases}$

Where $l_{i}$ and $u_{i}$ are, respectively, lower and upper tolerance limit for goal $i, g_{i}$ is the aspiration level of goal $i$
With the MAXMIN approach of Zimmermann (1978), the FGP can be expressed as follows:

$\max \lambda$

subject to.

$$
\begin{aligned}
& \lambda \leq \mu_{i}\left(f_{i}(X)\right) \quad i=1,2,3, \ldots, n \\
& A X \leq b, X \geq 0
\end{aligned}
$$

Where $\lambda$, is an additional continuous variable.

\section{FUZZY TOPSIS}

Since the preferred ratings usually refer to the subjective uncertainty, it is natural to extend TOPSIS to consider the situation of fuzzy numbers. Fuzzy TOPSIS can be intuitively extended by using the fuzzy arithmetic operations as follows. Assume that a decision group has $K$ DMs and the fuzzy ratings of all decision maker preferences are trapezoidal fuzzy member, $\tilde{R}=\left(a_{k}, b_{k y}, c_{k y}, d_{k}\right), k=1,2, \ldots k$ then the aggregated fuzzy rating can be defined as:

$\widetilde{R}=\left(a_{y}, b_{y} c_{y} d\right), k=1_{y} 2_{y} \ldots x_{y} k$,

where $a=\min _{k}\left\{a_{k}\right\}, b=\frac{\sum_{k=1}^{\bar{k}} b_{k}}{k}$

$c=\frac{\sum_{k=1}^{k} c_{k}}{k}, \mathrm{~d}=\max _{k}\left\{d_{k}\right\}$.

Let the fuzzy rating and importance weight of the $k$ th DM be $\tilde{x}_{i j k}=\left(a_{i j k^{p}} b_{i j k^{y}} c_{i j k^{y}} d_{i j k}\right)$, and

$\widetilde{w}_{j k}=\left(\widetilde{w}_{j k 1}, \widetilde{w}_{j k 2}, \widetilde{w}_{j k 3}, \widetilde{w}_{j k 4}\right)$,

where $i=1_{y} 2_{y} \ldots m_{j} j=1,2, \ldots n$ respectively. Therefore, the aggregated fuzzy ratings, $\tilde{x}_{i j}$ of alternatives with respect to each criterion can be calculated as (Chen et al., 2006):

$\tilde{x}_{i j}=\left(a_{i j}, b_{i j}, c_{i j y} d_{i j}\right)$

where $a_{i j}=\min _{k}\left\{a_{i j k}\right\}, b_{i j}=\frac{\sum_{k=1}^{k} b_{i j k}}{k}$ 
$c_{i j}=\frac{\sum_{k=1}^{k} c_{i j k}}{k}{ }_{j} d_{i j}=\max _{k}\left\{d_{i j k}\right\} \quad$ and $\quad$ the aggregated fuzzy weights, $\widetilde{w}_{j}$, of each criterion can be calculated as (Chen et al., 2006):

$\widehat{w}_{j}=\left(\widetilde{w}_{j 1}, \widehat{w}_{j 2}, \widehat{w}_{j 3}, \widehat{w}_{j 4}\right)$

Where $w_{j 1}=\min _{k}\left\{w_{j k 1}\right\}, w_{j 2}=\frac{\sum_{k=1}^{\mathbb{k}} w_{j k 2}}{k}$,

$w_{j 3}=\frac{\sum_{k=1}^{k} w_{j k 3}}{k}, w_{j 4}=\max \left\{w_{j k 4}\right\}$.

As stated above, a supplier-selection problem can be concisely expressed in matrix format as follows:

$$
\begin{aligned}
& \widetilde{\mathrm{x}}=\left[\begin{array}{cccc}
\widetilde{x}_{11} & \tilde{x}_{12} & \ldots & \widetilde{x}_{1 n} \\
\widetilde{x}_{21} & \widetilde{x}_{22} & \ldots & \widetilde{x}_{23} \\
\vdots & \vdots & . . & \vdots \\
\widetilde{x}_{m 1} & \widetilde{x}_{m 2} & \ldots & \tilde{x}_{m n}
\end{array}\right], \\
& \widetilde{\mathrm{W}}=\left[\begin{array}{llll}
\widetilde{w}_{1} & \widetilde{w} 2 & \ldots & \widetilde{w}_{n}
\end{array}\right]
\end{aligned}
$$

To avoid complexity of mathematical operations in a decision process, the linear scale transformation is used here to transform the various criteria scales into comparable scales. The set of criteria can be divided into benefit criteria (the larger the rating, the greater the preference) and cost criteria (the smaller the rating, the greater the preference). Therefore, the normalized fuzzy-decision matrix can be represented as:

$$
\tilde{R}=\left[\tilde{r}_{i j}\right], \quad i=1,2, \ldots, m, \quad j=1,2, \ldots . n
$$

Where the $\tilde{T}_{i j}$ is the normalized value of

$\tilde{x}_{i j}=\left(a_{i j}, b_{i j}, c_{i j}, d_{i j}\right)$, which be calculated as follows:

If the $j$ th criterion is a benefit, then: $\tilde{r}_{i j}=\left(a_{i j} / d_{j}^{*}, b_{i j} / d_{j}^{*}, c_{i j} / d_{j}^{*}, d_{i j} / d_{j}^{*}\right)$

If the $j$ th criterion is a cost, then

$$
\tilde{r}_{i j}=\left(a_{j}^{-} / d_{i j}, a_{j}^{-} / c_{i j}, a_{j}^{-} / b_{i j}, a_{j}^{-} / a_{i j}\right)
$$

Where $d_{j}^{*}=\max d_{i j}, a_{j}^{-}=\min a_{i j}$

A weighted normalized fuzzy-decision matrix can be constructed according to the normalized fuzzydecision matrix as follows:

$\tilde{V}=\left[\tilde{v}_{i j}\right]_{m \times n}$

Where $\tilde{v}_{i j}=\tilde{x}_{i j} \otimes \tilde{w}_{j}, \quad i=1,2, \ldots, m, \quad j=1,2, \ldots . . n$

After constructing a weighted normalized fuzzy decision matrix, the fuzzy positive-ideal solution (FPIS), $S^{+}$and the fuzzy negative- ideal solution (FNIS), $S^{-}$, can be calculated as follows:

$$
\begin{aligned}
& S^{+}=\left(\tilde{v}_{1}^{+}, \tilde{v}_{2}^{+}, \tilde{v}_{3}^{+}, \ldots . \tilde{v}_{n}^{+}\right), \text {and } \\
& S^{-}=\left(\tilde{v}_{1}^{-}, \tilde{v}_{2}^{-}, \tilde{v}_{3}^{-}, \ldots . \tilde{v}_{n}^{-}\right)
\end{aligned}
$$

Where $\tilde{v}_{j}^{+}=\max \left\{\tilde{v}_{i j}^{+}\right\}$, and $\tilde{v}_{j}^{-}=\min \left\{\tilde{v}_{i j}^{-}\right\}$.

The distance of each alternative from $S^{+}$and $S^{-}$can be calculated as:

$$
\begin{aligned}
& d_{i}^{+}=\sum_{j=1}^{n} d\left(\tilde{v}_{i j}, \tilde{v}_{j}^{+}\right), \quad i=1,2, . ., m, \text { and } \\
& d_{i}^{-}=\sum_{j=1}^{n} d\left(\tilde{v}_{i j}, \tilde{v}_{j}^{-}\right), \quad i=1,2, . ., m
\end{aligned}
$$

Where $\mathrm{d}(.,$.$) represents the distance measurement$ between two fuzzy numbers. Finally, the closeness coefficients $\left(C C_{i}\right)$ of each supplier according to distance from the fuzzy positive ideal solution (FPIS), $S^{+}$and the fuzzy negative ideal solution (FNIS), $S^{-}$, can be calculated as:

$$
C C_{i}=d_{i}^{-} /\left(d_{i}^{+}+d_{i}^{-}\right), \quad i=1,2, \ldots, m,
$$

Where $C C_{i}$ range belongs to the closed interval $[0,1]$

\section{FUZZY MULTI CHOICE GOAL PROGRAMMING (FMCGP)}

The MCGP method proposed by Chang (2007) allows DMs to set multiple scalar aspiration levels for each goal to avoid the underestimation of goal setting in the initial stage of decision problem. In 
order to solve the above mentioned problem, the revised MCGP approach has recently been introduced by Chang (2008). The revised MCGP represents a linear form of program which can be easily solved using common linear programming packages, not requiring the use of integer programming packages. The fuzzy multi choice goal programming mathematical model for the supplier selection is obtained as follows:

$\operatorname{Min} \sum_{i=1}^{n}\left(\alpha_{i} d_{i}^{+}+\beta_{i} d_{i}^{-}\right)+\sum_{i}^{n}\left(\mathrm{e}_{\mathrm{i}}^{+}+e_{i}^{-}\right)$

Subject to

$$
\begin{aligned}
& f_{i}(X)-d_{i}^{+}+d_{i}^{-}=g_{\mathrm{i}}, i=1,2, \ldots, n \\
& g_{i}-\mathrm{e}_{i}^{+}+\mathrm{e}_{i}^{-}=\mathrm{g}_{\mathrm{i}, \max }, \quad i=1,2, \ldots, n
\end{aligned}
$$

For maximization

$$
g_{i}-\mathrm{e}_{i}^{+}+\mathrm{e}_{i}^{-}=\mathrm{g}_{\mathrm{i}, \min }, \quad i=1,2, \ldots, n
$$

For minimization

$$
\begin{aligned}
& g_{\mathrm{i}, \text { min }} \leq g_{\mathrm{i}} \leq g_{\mathrm{i}, \max }, \quad i=1,2, \ldots, n \\
y_{i}= & \frac{g_{i, \max }-f_{i}(x)}{g_{i, \max }-g_{i, \min }}
\end{aligned}
$$

For maximization

$$
y_{i}=\frac{f_{i}(x)-g_{i, \min }}{g_{i, \max }-g_{i, \min }}
$$

For minimization

$$
y_{i}-y_{j}=K_{i j} \quad \text { (Goal } i \text { is }
$$

more important than goal $j$.)

$d_{i}^{+}, d_{i}^{-}, \mathrm{e}_{\mathrm{i}}^{+}, e_{i}^{-} \geq 0, \quad i=1,2, \ldots, n$

$X \in F$ ( $F$ is a feasible set)

Where $\alpha_{i,} \quad \beta_{i}$ is the weight for over and under achievement of $i$ goal, $d_{i}^{+}$is the over-achievements of the $i$ th goal, $d_{i}^{-}$is the under-achievements of the $i$ th goal, $e_{i}^{+}$is the over-achievement of the highest (lowest) possible value of membership function, $e_{i}$ is the under-achievement of the highest (lowest) possible value of membership function, $f_{i}(x)$ the linear function of the $i$ th goal, $g_{i}$ the aspiration level of the $i$ th goal in FMCGP, $g_{i \text {,min }}$ the lower bound aspiration for the $i$ th goal, $g_{i, \max }$ the upper bound aspiration for the $i$ th goal, and $y_{i}$ is the ratio of the achievement in the $i$ th goal

Equation (17) represents the goal of the proposed model which is minimizing the over and under achievement goal deviation. Equations (18)-(21) are adopted from revised MCGP (Chang, 2008). Equation (18) represents the linear function of the goal $i$ in the model which derided to reach the required aspiration level $g_{i}$. Equation $(19,20)$ represents the relation between the required aspiration level and maximum and minimum bound of aspiration level in case of maximize and minimize respectively. Equation (21) represents the aspiration level limits (boundary). Equation $(22,23)$ represents the achievement ratio (rate) of goal in maximizes and minimizes case. Equation (24), a DM can determine the satisfaction level of fuzzy relations between goal $i$ and goal $j$, where the preemptive priority level of goal $i$ is higher than the preemptive priority level of goal $j$. Kij represents the deviation between goal $i$ and goal $j$. The solution procedure starts by inputting DM's supplier selection goals with satisfactory levels and criteria, and then developing a FMCGP model to get the ideal order quantity from suppliers.

\section{THE PROPOSED MODEL}

The proposed model is an integrated approach of fuzzy TOPSIS and FMCGP for supplier selection. The proposed model considers DM's preference and experience for supplier selection criteria, also includes various tangible constraints, for example, the buyer's budget, suppliers' capacity and delivery time. On the other hand, fuzzy TOPSIS approach helps to convert DMs' preference and experience to meaningful results by applying linguistic values to assess each criterion and alternative suppliers. Integration with FMCGP enables to assign order quantities to each supplier by considering the total value created from the procurement. According to Chang (2007, 2008), Dutta and Murthy (2010), and Bankian-T et al. (2011) FMCGP allows DMs to set multi choice aspiration levels (MCAL) for each goal (i.e., one goal mapping multiple aspiration levels) to avoid underestimation or overestimation of decision making.

The algorithm of the multi-person multi-criteria decision-marking with fuzzy TOPSIS and FMCGP method for dealing with the supplier selection is given as follows:

Step 1. Choose the appropriate linguistic variables for the importance weight of selection criteria and the linguistic ratings for suppliers. 
Step 2. Aggregate the weigh $\widetilde{w}_{j}$ of criterion $C_{j}$ and pool the DMs' ratings to get the aggregated fuzzy rating $\widetilde{x}_{i j}$ of supplier $S_{\mathrm{i}}$ under criterion $C_{j}$.

Step 3. Construct the fuzzy-decision matrix and normalize the matrix.

Step 4. Construct weighted normalized fuzzydecision matrix.

Step 5. Determine FPIS and FNIS.

Step 6. Calculate the distance of each supplier from FPIS and FNIS, respectively.

Step 7. Calculate the closeness coefficient $\left(C C_{i}\right)$ of each supplier.

Step 8. According to the closeness coefficients obtained from Step 7 for each supplier, build the integrated model to find the best suppliers and their optimum order quantities. In order to find the best order quantities, the total value created from the procurement (TVP) should be maximized.

\section{CASE STUDY}

Refer to case study in an integrated fuzzy TOPSIS and MCGP approach to supplier selection in supply chain management by Liao and Kao (2011). The company Formosa Watch Co., Ltd. (FWCL) is a large, well-known manufacturer that sells watches in its own chain stores in Asia. For developing new products, its board of directors wishes to select material suppliers to purchase key components in order to achieve the competitive advantage in the market. A decision committee including three DMs $\left(D_{1}, D_{2}, D_{3}\right)$ has been formed to select a supplier from four qualified suppliers (S1; S2; S3; S4). From a complete set of criteria, FWCL chooses five supplier selection criteria for the present case: Relationship closeness $\left(C_{1}\right)$, Quality of product $\left(C_{2}\right)$, Delivery capabilities $\left(\mathrm{C}_{3}\right)$, Warranty level $\left(\mathrm{C}_{4}\right)$, and Experience time $\left(\mathrm{C}_{5}\right)$. In this study, the hierarchy structure of the decision problem is shown in Fig. 4. According to the sales record in the last 5 years and the sales forecast by FWCL, the CEO and top managers of FWCL have established that,

the total value of procurement (TVP) at least 3500 units from procurement; and the more the better, the total cost of procurement of less than 53,200 thousand dollars; and the less the better, for achieving the procurement levels, the delivery time (per batch) from supplier is set between 4 and 7 days; the less the better, for seeking differentiation strategy (i.e., quality leadership), maintain the current procurement level of less than 5000 units, and available budget more than $\$ 46000$. In addition, the coefficients of variables in model are given by FWCL's database calculated from the last 5 years record. The unit material cost for suppliers S1, S2, $\mathrm{S} 3$, and $\mathrm{S} 4$ are $\$ 12, \$ 9, \$ 15$, and $\$ 6$, respectively, and the capacities of the four candidate suppliers S1, S2, S3, and S4 are 2700, 3500, 2300, and 3100 units, respectively. Furthermore, the delivery time levels of the four candidate suppliers are 2.5, 4, 6, and 3 days, respectively. The integrated fuzzy TOPSIS and FMCGP method is applied to solve this problem, and the computational procedure is summarized as follows

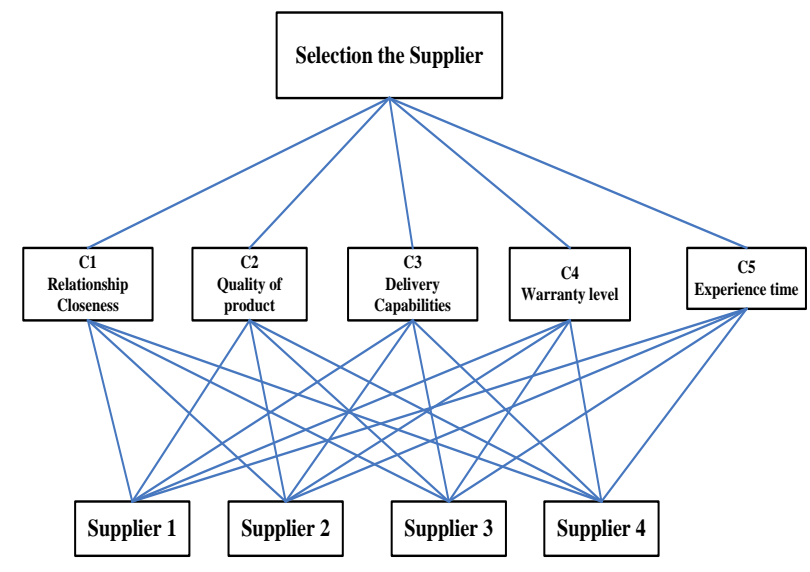

Fig. 4. Hierarchy structure of decision problem

1. Three DMs use the linguistic variables shown in Fig. 2 to assess the importance weight of each supplier criterion; the results of the weights are presented in Table 1 .

2. Three DMs use the linguistic variables shown in Fig. 3 to rate suppliers with respect to each criterion; the results of the ratings are shown in Table 2.

3. The linguistic evaluations shown in Tables 1 and 2 are converted into trapezoidal fuzzy numbers to construct a fuzzy-decision matrix and determine the fuzzy weight of each criterion, as shown in Table 3

4. Table 4 is a normalized fuzzy-decision matrix, which used to construct a weighted normalized fuzzy decision matrix as shown in Table 5.

5. FPIS and FNIS are determined as shown in table 6. 6. Calculate the distance of each supplier from FPIS and FNIS with respect to each criterion, respectively, as shown in Tables 7, 8 .

7. Calculate the closeness coefficients of each supplier, as shown in Table 9

8. According to the closeness coefficients $(\mathrm{CCi} ; \mathrm{i}=$ $1 ; 2 ; 3 ; 4)$ obtained from Step 7 for each supplier, 
build the FMCGP model to identify the best suppliers and optimum order qualities. Similar to Ghodsypour and O'Brien (2001) and Guneri, Yucel, and Ayyildiz (2009), supplier weights (or priority values) are used as closeness coefficients in an objective function to allocate order quantities among suppliers such that the TVP is maximized.

Table 1. Importance weights of criteria for DMs

\begin{tabular}{|c|c|c|c|}
\hline Criteria & D1 & D2 & D3 \\
\hline $\mathrm{C} 1$ & $\mathrm{H}$ & $\mathrm{H}$ & $\mathrm{H}$ \\
\hline $\mathrm{C} 2$ & $\mathrm{H}$ & $\mathrm{H}$ & $\mathrm{H}$ \\
\hline $\mathrm{C} 3$ & $\mathrm{VH}$ & $\mathrm{VH}$ & $\mathrm{VH}$ \\
\hline $\mathrm{C} 4$ & $\mathrm{VH}$ & $\mathrm{VH}$ & $\mathrm{H}$ \\
\hline $\mathrm{C} 5$ & $\mathrm{H}$ & $\mathrm{H}$ & $\mathrm{H}$ \\
\hline
\end{tabular}

Table 2. Ratings of four candidates by DMs according to five criteria

\begin{tabular}{|c|c|c|c|c|}
\hline Criteria & Supplier & D1 & D2 & D3 \\
\hline \multirow[t]{4}{*}{$\mathrm{C} 1$} & S1 & $\mathrm{G}$ & G & $\mathrm{G}$ \\
\hline & $\mathrm{S} 2$ & MG & MG & $\mathrm{G}$ \\
\hline & S3 & $\mathrm{VG}$ & VG & $\mathrm{G}$ \\
\hline & S4 & $\mathrm{G}$ & G & $\mathrm{G}$ \\
\hline \multirow[t]{4}{*}{$\mathrm{C} 2$} & S1 & G & G & VG \\
\hline & S2 & $G$ & $G$ & $\mathrm{G}$ \\
\hline & S3 & VG & VG & VG \\
\hline & S4 & $G$ & MG & $\mathrm{VG}$ \\
\hline \multirow[t]{4}{*}{$\mathrm{C} 3$} & $\mathrm{~S} 1$ & VG & VG & $\mathrm{MG}$ \\
\hline & $\mathrm{S} 2$ & $\mathrm{G}$ & $G$ & $\mathrm{G}$ \\
\hline & S3 & $\mathrm{MG}$ & $\mathrm{MG}$ & $\mathrm{MG}$ \\
\hline & S4 & MG & MG & $\mathrm{G}$ \\
\hline \multirow[t]{4}{*}{$\mathrm{C} 4$} & S1 & VG & VG & VG \\
\hline & $\mathrm{S} 2$ & $G$ & MG & $\mathrm{VG}$ \\
\hline & S3 & $\mathrm{VG}$ & $G$ & $G$ \\
\hline & $\mathrm{S} 4$ & $\bar{G}$ & G & $\mathrm{G}$ \\
\hline \multirow[t]{4}{*}{$\mathrm{C} 5$} & S1 & VG & VG & $\mathrm{G}$ \\
\hline & S2 & $\mathrm{G}$ & $\mathrm{G}$ & $\mathrm{G}$ \\
\hline & S3 & MG & MG & $\mathrm{G}$ \\
\hline & S4 & MG & MG & $\mathrm{G}$ \\
\hline
\end{tabular}

Table 3. Fuzzy decision-matrix and fuzzy weights of four candidates.

\begin{tabular}{|c|c|c|c|c|c|}
\hline & C1 & $\mathrm{C2}$ & $\mathbf{C 3}$ & $\mathrm{C4}$ & $\mathrm{C5}$ \\
\hline S1 & $(7,8,8,9)$ & $(5,7,8,10)$ & $(5,8,9,10)$ & $(8,9,10,10)$ & $(7,8.7,9.3,10)$ \\
\hline S2 & $(5,6.7,7.3,9)$ & $(\mathbf{7 , 8 , 8 , 9 )}$ & $(\mathbf{7 , 8 , 8 , 9 )}$ & $(\mathbf{7 , 8 , 8 , 9 )}$ & $(\mathbf{7 , 8 , 8 , 9 )}$ \\
\hline S3 & $\begin{array}{l}(8,8.7,9.3,10) \\
\end{array}$ & $(8,9,10,10)$ & $(5,6,7,8)$ & $\begin{array}{l}(7,8.3,8.7,10) \\
\end{array}$ & $(5,6,7,8)$ \\
\hline S4 & $(7,8,8,9)$ & $(5,7.7,8.3,10)$ & $5,6.7,7.3,9)$ & $(\mathbf{7 , 8 , 8 , 9 )}$ & $(5,6.7,7.3,9)$ \\
\hline Weight & $(0.7,0.8,0.8,0.9)$ & $(0.7,0.8,0.8,0.9)$ & $(0.7,0.9,1.0,1.0)$ & $(0.7,0.87,0.93,1.0)$ & $(0.7,0.8,0.8,0.9)$ \\
\hline
\end{tabular}

Table 4. Normalized fuzzy decision-matrix.

\begin{tabular}{|c|c|c|c|c|c|}
\hline & C1 & $\mathrm{C2}$ & $\mathrm{C3}$ & $\mathrm{C4}$ & $\mathrm{C5}$ \\
\hline $\mathrm{S} 1$ & $(0.7,0.8,0.8,0.9)$ & \begin{tabular}{|l|l|}
$(0.5,0.7,0.8,1)$ \\
\end{tabular} & $(0.5,0.8,0.9,1)$ & $(0.8,0.9,1,1)$ & $(0.7,0.87,0.93,1)$ \\
\hline $\mathrm{S} 2$ & $\begin{array}{l}(0.5,0.67,0.73,0.9) \\
\end{array}$ & $\begin{array}{l}(0.7,0.8,0.8,0.9) \\
\end{array}$ & $\begin{array}{l}(0.7,0.8,0.8,0.9) \\
\end{array}$ & $\begin{array}{l}(0.7,0.8,0.8,0.9) \\
\end{array}$ & $(0.7,0.8,0.8,0.9)$ \\
\hline S3 & $(0.8,0.87,0.93,1)$ & $(0.8,0.9,1,1)$ & $(0.5,0.6,0.7,0.8)$ & $(0.7,0.83,0.87,1)$ & $(0.5,0.6,0.7,0.8)$ \\
\hline $\mathrm{S} 4$ & $(0.7,0.8,0.8,0.9)$ & $(0.5,0.77,0.83,1)$ & $(0.5,0.67,0.73,0.9)$ & $(0.7,0.8,0.8,0.9)$ & $(0.5,0.67,0.73,0.9)$ \\
\hline
\end{tabular}

Table 5. Weighted normalized fuzzy decision-matrix.

\begin{tabular}{|c|c|c|c|c|c|}
\hline & $\mathbf{C 1}$ & $\mathrm{C2}$ & $\mathbf{C 3}$ & $\mathrm{C4}$ & $\mathbf{C 5}$ \\
\hline S1 & $(0.49,0.64,0.64,0.81)$ & $(0.35,0.56,0.64,0.9)$ & $(0.35,0.72,0.9,1)$ & $(0.56,0.78,0.93,1)$ & $(0.49,0.69,0.75,0.9)$ \\
\hline $\mathrm{S} 2$ & $(0.35,0.35,0.59,0.81)$ & $(0.49,0.64,0.64,0.81)$ & $\begin{array}{l}(0.49,0.72,0.8,0.9) \\
\end{array}$ & $(0.49,0.69,0.75,0.9)$ & $(0.49,0.64,0.64,0.81)$ \\
\hline S3 & $(0.65,0.69,0.75,0.9)$ & $(0.56,0.72,0.8,0.9)$ & $(0.35,0.54,0.7,0.8)$ & $(0.49,0.72,0.81,1)$ & $(0.35,0.48,0.56,0.72)$ \\
\hline S4 & 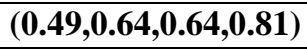 & $(0.35,0.61,0.67,0.9)$ & $(0.35,0.6,0.73,0.9)$ & $(0.49,0.69,0.75,0.9)$ & \begin{tabular}{|l}
$(0.35,0.53,0.59,0.81)$ \\
\end{tabular} \\
\hline
\end{tabular}

Table 6. FPIS and FNIS

\begin{tabular}{|l|c|c|c|c|c|}
\hline $\mathrm{S}^{+}=$ & $(\mathbf{0 . 9}, 0.9,0.9,0.9)$ & $(0.9,0.9,0.9,0.9)$ & $(\mathbf{1 , 1 , 1 , 1 )}$ & $(\mathbf{1 , 1}, 1,1)$ & $(\mathbf{0 . 9}, 0.9,0.9,0.9)$ \\
\hline $\mathrm{S}^{-}=$ & $(\mathbf{0 . 3 5 , 0 . 3 5 , 0 . 3 5 , 0 . 3 5 )}$ & $(\mathbf{0 . 3 5 , 0 . 3 5 , 0 . 3 5 , 0 . 3 5 )}$ & $\mathbf{( 0 . 3 5 , 0 . 3 5 , 0 . 3 5 , 0 . 3 5 )}$ & $(\mathbf{0 . 4 9 , 0 . 4 9 , 0 . 4 9 , 0 . 4 9 )}$ & $(\mathbf{0 . 3 5 , 0 . 3 5 , 0 . 3 5 , 0 . 3 5 )}$ \\
\hline
\end{tabular}


Table 7. Distances between FPIS and supplier ratings.

\begin{tabular}{|c|c|c|c|c|c|}
\hline & $\mathrm{C} 1$ & $\mathrm{C} 2$ & $\mathrm{C} 3$ & $\mathrm{C} 4$ & $\mathrm{C} 5$ \\
\hline $\mathrm{d}\left(\mathrm{S} 1, \mathrm{~S}^{+)}\right.$ & 0.28 & 0.35 & 0.36 & 0.25 & 0.24 \\
\hline $\mathrm{d}\left(\mathrm{S} 2, \mathrm{~S}^{+)}\right.$ & 0.37 & 0.28 & 0.31 & 0.33 & 0.28 \\
\hline $\mathrm{d}\left(\mathrm{S} 3, \mathrm{~S}^{+)}\right.$ & 0.21 & 0.2 & 0.44 & 0.31 & 0.40 \\
\hline $\mathrm{d}\left(\mathrm{S}_{4}, \mathrm{~S}^{+)}\right.$ & 0.28 & 0.33 & 0.41 & 0.33 & 0.37 \\
\hline
\end{tabular}

Table 8. Distances between FNIS and supplier ratings.

\begin{tabular}{|c|c|c|c|c|c|}
\hline & $\mathrm{C} 1$ & $\mathrm{C} 2$ & $\mathrm{C} 3$ & $\mathrm{C} 4$ & $\mathrm{C} 5$ \\
\hline $\mathrm{d}\left(\mathrm{S} 1, \mathrm{~S}^{-}\right)$ & 0.32 & 0.33 & 0.46 & 0.37 & 0.39 \\
\hline $\mathrm{d}\left(\mathrm{S} 2, \mathrm{~S}^{-)}\right.$ & 0.27 & 0.32 & 0.41 & 0.26 & 0.32 \\
\hline $\mathrm{d}\left(\mathrm{S} 3, \mathrm{~S}^{-}\right)$ & 0.39 & 0.41 & 0.30 & 0.32 & 0.22 \\
\hline $\mathrm{d}\left(\mathrm{S} 4, \mathrm{~S}^{-}\right)$ & 0.32 & 0.34 & 0.36 & 0.26 & 0.27 \\
\hline
\end{tabular}

Table 9. Computation of $d_{i}^{+}, d_{i}{ }^{-}$and $\mathbf{C C}_{i}$.

\begin{tabular}{|c|c|c|c|c|}
\hline & $\mathrm{d}_{\mathrm{i}}^{+}$ & $\mathrm{d}_{\mathrm{i}}^{-}$ & $\mathrm{d}_{\mathrm{i}}^{+}+\mathrm{d}_{\mathrm{i}}^{-}$ & $\mathrm{CC}_{\mathrm{i}}$ \\
\hline $\mathrm{d}\left(\mathrm{S} 1, \mathrm{~S}^{-}\right)$ & 1.86 & 1.48 & 3.34 & 0.558 \\
\hline $\mathrm{d}\left(\mathrm{S} 2, \mathrm{~S}^{-}\right.$ & 1.58 & 1.57 & 3.14 & 0.502 \\
\hline $\mathrm{d}\left(\mathrm{S} 3, \mathrm{~S}^{-}\right)$ & 1.65 & 1.55 & 3.20 & 0.516 \\
\hline $\mathrm{d}\left(\mathrm{S} 4, \mathrm{~S}^{-)}\right.$ & 1.55 & 1.71 & 3.27 & 0.476 \\
\hline
\end{tabular}

Using an integrated fuzzy TOPSIS and FMCGP approach, this problem can be formulated as follows:

$$
\begin{aligned}
& \min \sum_{i=1}^{n} d_{1}^{+}+d_{1}^{-}+d_{2}^{+}+d_{2}^{-}+d_{3}^{+}+d_{3}^{-}+d_{4}^{+}+ \\
& d_{4}^{-}+e_{1}^{+}+e_{1}^{-}+e_{2}^{+}+e_{2}^{-}
\end{aligned}
$$

Subject to

$0.558 x_{1}+0.502 x_{2}+0.516 x_{3}+0.476 x_{4}-$

$d_{1}^{+}+d_{1}^{-} \geq 3500$

$$
\begin{aligned}
& 12 x_{1}+9 x_{2}+15 x_{3}+6 x_{4}-d_{2}^{+}+d_{2}^{-}=y_{1} \\
& y_{1}-\mathrm{e}_{1}^{+}+\mathrm{e}_{1}^{-}=46000 \\
& y_{1} \geq 46000 \\
& y_{1} \leq 53200 \\
& 2.5 x_{1}+4 x_{2}+6 x_{3}+3 x_{4}-d_{3}^{+}+d_{3}^{-}=y_{2} \\
& y_{2}-\mathrm{e}_{2}^{+}+\mathrm{e}_{2}^{-}=4 \\
& y_{2} \geq 4 \\
& y_{2} \leq 7 \\
& x_{1}+x_{2}+x_{3}+x_{4}-d_{4}^{+}+d_{4}^{-}=500 \\
& x_{1} \leq 2700 \\
& x_{2} \leq 3500 \\
& x_{3} \leq 2300 \\
& x \leq 3100 \\
& y_{1}=\frac{f_{1}(x)-46000}{53200-46000} \\
& y_{2}=\frac{f_{2}(x)-4}{7-4} \\
& d_{i}^{+}, d_{i}^{-}, \mathrm{e}_{\mathrm{i}}^{+}, e_{i}^{-} \geq 0, \quad i=1,2, \ldots, n \\
& X \in F \text { ( } F \text { is a feasible set) }
\end{aligned}
$$

Solve the above case study using an integrated fuzzy TOPSIS and FMCGP approach, FGP and an integrated Fuzzy TOPSIS and MCGP approach using Lingo Software. The obtained results are summarized in table 10 , and table11.

Table 10. The maximize and minimize of case study

\begin{tabular}{|l|c|c|c|c|}
\hline & \multicolumn{2}{|c|}{ Proposed Model } & \multicolumn{2}{c|}{ FGP } \\
\cline { 2 - 5 } & Goal 1 & Goal 2 & Goal 1 & Goal 2 \\
\hline Max value & 53200 & 46000 & 66900 & 24600 \\
\hline Min Value & 35000 & 20000 & 22200 & 9150 \\
\hline Quantity in Max & & & $\mathrm{X} 1=2700, \mathrm{x} 3=2300$ & $\mathrm{X} 2=2700, \mathrm{x} 3=2300$ \\
\hline Quantity in Min & & & $\mathrm{X} 2=400, \mathrm{x} 4=3100$ & $\mathrm{X} 1=2700, \mathrm{x} 4=800$ \\
\hline
\end{tabular}

Table 11. Comparison between different approaches

\begin{tabular}{|c|c|c|c|c|c|c|}
\hline \multirow{2}{*}{ Method } & \multicolumn{2}{|c|}{ Proposed Model } & \multicolumn{2}{c|}{ FGP } & \multicolumn{2}{c|}{ Liao and Kao (2011) } \\
\cline { 2 - 7 } & Goal 1 & Goal 2 & Goal 1 & Goal 2 & Goal 1 & Goal 2 \\
\hline Obtained result & 4600 & 4 & 58800 & 24600 & 46005 & 4.39 \\
\hline Quantity & \multicolumn{2}{|c|}{$\mathrm{X} 2=3500 ; \mathrm{x} 3=966$} & \multicolumn{2}{|c|}{$\mathrm{X} 2=2700, \mathrm{x} 3=2300$} & $\mathrm{X} 1=2700, \mathrm{x} 3=907$ \\
\hline Achievement of each goals & 1.00 & 1.00 & 0.8187919 & 1.00 & 1.00 & 0.87 \\
\hline
\end{tabular}




\section{The Egyptian Int. J. of Eng. Sci. and Technology Vol.15, No. 2 (May 2012)}

From the above results, the proposed model obtained best solution rather than other two methods.

\section{CONCLUSION}

In this paper, an integrated fuzzy TOPSIS and FMCGP approach for supplier selection is presented. In general, supplier evaluation is vague and uncertain, and so fuzzy set theory helps to convert DM preferences and experiences into meaningful results by applying linguistic values to measure each criterion with respect to every supplier. Employing Fuzzy TOPSIS and FMCGP approach enables DMs to assign order quantities to each supplier and achievement the required goals. An integrated approach allows for the vague aspirations of DMs to set multiple aspiration levels for supplier selection problems. The proposed approach is presented through a case study; the result obtains better performance level than other compared methods.

\section{REFERENCES}

1. Aköz, O., \& Petrovic, D. (2007). "A fuzzy goal programming method with imprecise goal hierarchy". European Journal of Operational Research, 181(3), 1427-1433.

2. Anion, F. \& Güng r, Z.,(2001). "An Application of Fuzzy Goal Programming to A Multiobjective Project Nefcwork Problem". Fuzzy Sets and Systems, 119,49-58

3. Bankian-T, B., Shahanghi,K., \& Jabalameli, M. S., (2011). "Fuzzy multi-choice goal programming". Applied mathematical modeling, DOI:10.1016/J.apm.2011.08.040

4. Buckley, J. J. (1985). "Fuzzy hierarchical analysis". Fuzzy Sets and Systems, 17, 233247.

5. Chan, F. T. S., \& Kumar, N. (2007). "Global supplier development considering risk factors using fuzzy extended AHP-based approach". Omega, 35(4), 417-431.

6. Chang, C. T. (2008). "Revised multi-choice goal programming". Applied Mathematical Modelling, 32, 2587-2595.

7. Chang, C.-T, \& Lin, T. C. (2009). "Interval goal programming for S-shaped penalty function". European Journal of Operational Research, 199, 9-20

8. Chang, C.T. (2007). "Multi-choice goal programming”. Omega 35(4), 389-396.

9. Charnes, A. \& Cooper, W.W. (1961). "Management model and industrial application of linear programming". New York: Wiley.

10. Chen, C. T. (2000). Extensions of the TOPSIS for group decision-making under fuzzy environment. Fuzzy Sets and Systems, 114, 1-9.

11. Chen, C. T., Lin, C. T., \& Huang, S. F. (2006). "A fuzzy approach for suppler evaluation and selection in supply chain management". International Journal of Production Economics, 102, 289-301.

12. Chen, L.-H., \& Tsai, F.-C. (2001). "Fuzzy goal programming with different importance and priorities". European Journal of Operational Research, 133(3), 548-556.

13. Curry, B., \& Lazzari, L. (2009). "Fuzzy consideration sets: a new approach based on direct use of consumer preferences". International Journal of Applied Management Science, 1(4), 420-436.

14. Demirtas, E.A, \& Üstün, Ö.(2008). “An integrated multi objective decision making process for supplier selection and order allocation". Omega, 36, 76-90

15. Dickson, G. W. (1966). "An analysis of supplier selection system and decision". Journal of Purchasing, 2(1), 5-17.

16. Dobler, D. W., Lee, L., \& Burt, N. (1990). "Purchasing and materials management: text and cases". New York: McGraw-Hill.

17. Dutta, D. \& Murthy,S. (2010). "multi-choice goal programming approach for fuzzy transportation problem". IJRAS2 (2) February, 132-139.

18. Ellram, L. (1990). "The supplier selection decision in strategic partnerships". Journal of Purchasing and Material Management, 26(1), 8-14

19. El-Wahed, W.F. \& Abo-Sinna, M.A., (2001). "A Hybrid Fuzzy-Goal Programming Approach to Multiple Objective Decision Making Problems". Fuzzy Sets and Systems, 119, 71-85

20. Evans, R. H. (1980). "Choice criteria revisited". Journal of Marketing, 44(1), 55-56.

21. Faez, F., Ghodsypour, S. H., \& O'brien, C. (2009). "Vendor selection and order allocation using an integrated fuzzy case-based reasoning and mathematical programming model". International Journal of Production Economics, 121(2), 395-408.

22. Fazlollahtabar, H. (2008). "Applying MultipleCriteria Decision Making methods for developing IT industry”. Int. J. Information and 
Decision Sciences, 1(1), 115-131.

23. Ghodsypour, S. H., \& O'Brien, C. (1998). “A decision support system for supplier selection using an integrated analytic hierarchy process and linear programming”. International Journal of Production Economics, 56-57, 199212

24. Ghodsypour, S. H., \& O’Brien, C. (2001). “The total cost of logistics in supplier selection, under conditions of multiple sourcing, multiple criteria and capacity constraint". International Journal of Production Economics, 73, 15-27.

25. Guneri, A. F., Yucel, A., \& Ayyildiz, G. (2009). "An integrated fuzzy-lp approach for a supplier selection problem in supply chain management". Expert Systems with Applications, 36(5), 9223-9228.

26. Ha, S. H., \& Krishnan, R. (2008). "A hybrid approach to supplier selection problem for the maintenance of a competitive supply chain". Expert Systems with Applications, 34(2), 1303-1311.

27. Hannan, E.L., (1981). "Some Further Comments on Fuzzy Priorities". Decision Science, 13, 337-339

28. Ignizio, J.P. (1976). "Goal programming and extensions”. Lexington Books, Lexington, MA.

29. Ignizio, J.P., (1985). "Introduction to linear goal programming”. Sage, Beverly, Hills, CA.

30. Iyer, A. V., \& Bergen, M. E. (1997). "Quick Response in Manufacturer-Retailer Channels". Management Science, 43(4), 559-570.

31. Kahraman, C., Cevik, S., Ates, N. Y., \& Güfer, M. (2007). "Fuzzy multi-criteria evaluation robotic systems". Computers \& Industrial Engineering, 52, 414-433.

32. Kokangul, A., \& Susuz, Z. (2009). "Integrated analytical hierarch process and mathematical programming to supplier selection problem with quality discount". Applied Mathematical Modelling, 33, 1417-1429.

33. Krajewsld, L. J., \& Ritzman, L. P. (1996). "Operations management strategy and analysis". London: Addison-Wesley Publishing Co..

34. Kumar, M., Vrat, P., \& Shankar, R. (2006). “A fuzzy programming approach for vendor selection problem in a supply chain". International Journal of Production Economics, 101, 273-285

35. Lai, Y-J. \& Hwang, C-L. (1994). "Fuzzy Multi Objective Decision Making: Methods and Applications". Springer-Verlag: Berlin.

36. Lee, S.M.(1972). "Goal programming for decision analysis”. Auerbach, Philadelphia,
$P A$.

37. Liao, C.N. (2009). "Formulating the multisegment goal programming”. Computers \& Industrial Engineering 56, 138-141.

38. Liao, C.N. \& Kao, H- P. (2011). “An integrated fuzzy TOPSIS and MCGP approach to supplier selection in supply chain management". Expert Systems with Applications, 38, 10803-10811

39. Lin, C.-C. (2004). "A weighted max-min model for fuzzy goal programming”. Fuzzy Sets and Systems, 142(3), 407-420.

40. Lin, H. T., \& Chang, W. L. (2008). "Order selection and pricing methods using flexible quantity and fuzzy approach for buyer evaluation”. European Journal of operational Research, 187(2), 415-428.

41. Liou, J. J. H., \& Chuang, M.-L. (2008). “A hybrid MCDM model for evaluating the corporate image of the airline industry". Int. J. Applied Management Science, 1(1), 41-54.

42. Lotfi, V., Yoon, Y.S, and Zionts, S. (1997). "Aspiration-based search algorithm (ABSALG) for multiple objective linear programming problems: theory and comparative tests". Management Science 43, 1047-1059.

43. Min, H. (1994). "International supplier selection: A multi-attribute utility approach”. International Journal of Physical Distribution \& Logistics Management, 24(5), 24-33.

44. Mohammed, W., (2000). "Chance Constrained Fuzzy Goal Programming With Right-hand Side Uniform Random Variable Coefficients". Fuzzy Sets and Systems, 109,107-110.

45. Narasimhan, $R$. and Rubin, P.A., (1984). "Fuzzy Goal Programming with Nested Priorities". Fuzzy Sets and Systems, 14,115-129

46. Narasimhan, R., (1980). "Goal Programming in A Fuzzy Environment”. Decision Science, 11, 325-336

47. Ö nüt, S., Kara, S. S., \& Isik, E. (2009). “Long term supplier selection using a combined fuzzy MCDM approach: A case study for a telecommunication company". Expert Systems with Applications, 36(2), 3887-3895.

48. Ohta, H. and Yamaguchi, T., (1996). "Linear Fractional Goal Programming in Consideration of Fuzzy Solution", European Journal of Operational Research, 92,157-165

49. Parra, M.A., Terol, A.B., Uría, M.VR. (2001). "A fuzzy goal programming approach to portfolio selection". European Journal of Operational Research, Volume 133,(2), 287-297

50. Pi, W. N., \& Low, C. (2005). "Supplier evaluation and selection using Taguchi loss 


\section{The Egyptian Int. J. of Eng. Sci. and Technology Vol.15, No. 2 (May 2012)}

functions". International Journal of Advanced Manufacturing Technology, 26, 155-160.

51. Porter, M. E. (1998). "Competitive strategy: techniques for analyzing industries and competitors". New York: The Free Press

52. Romero, C. (2001). "Extended lexicographic goal programming: a unifying approach”. Omega 29(1), 63-71.

53. Sarami, M., Mousavi, S. F., \& Sanayei, A. (2009). "TQM consultant selection in SMEs with TOPSIS under fuzzy environment”. Expert Systems with Applications, 36(2), 2742-2749.

54. Schonberger, R. J. (1982). “Japanese Manufacturing Techniques: Nine hidden lessons in simplicity". New York: The Free Press

55. Shin, H., Collier, D. A., \& Wilson, D. D. (2000). "Supplier management orientations and supplier/buyer performance”. Journal of Operations Management, 18, 317-333.

56. Shipley, D. D. (1985). “Reseller's supplier selection criteria for different consumer products". European Journal of Marketing, 19(7), 26-36

57. Tam, M. C. Y., \& Tummala, V. M. R. (2001). "An application of the AHP in vendor selection of a telecommunications system”. Omega, 29, 171-182.

58. Tamiz, M., Jones, D. \& Romero, C. (1998)." Goal programming for decision marking: an overview of the current state-of-the-art". European Journal of Operational Research 111(3), 567-581.

59. Tiwari, R.N., Dharmar, S. and Rao, J.R., (1986). "Priority Structure in Fuzzy Goal Programming", Fuzzy Sets and Systems, 19,251-259

60. Uría, M. VR, Caballero, R, Ruiz, F \& Romero, C.(2002). "Meta-goal programming". European Journal of Operatinal Research 136, 422-429.

61. Wang, H.-F. \& Fu, C.-C, (1997). "A Generalization of Fuzzy Goal Programming With Preemptive Structure", Computers \& Operations Research, 24,819-828

62. Wang, J. W., Cheng, C. H., \& Cheng, H. K. (2009). "Fuzzy hierarchical TOPSIS for supplier selection”. Applied Soft Computing, 9, 377-386.

63. Weber, C. L., Current, J. R., \& Benton, W. C. (1991). "Vendor selection criteria and methods". European Journal of Operational Research, 50(1), 2-18.

64. Willis, H. T., Huston, R. C., \& Pohlkamp, F. (1993). "Evaluation measures of just in time supplier performance”. Production and Inventory Management Journal, 34(2), 1-5.

65. Zadeh, L. (1965). "Fuzzy sets". Information and Control, 8, 338-353.

66. Zimmermann, H. J. (1978). “Fuzzy programming and linear programming with several objective functions". Fuzzy Sets and Systems, 1, 45-55. 